\title{
Identification of Antagonistic Bacteria Isolated from Thai Fermented Soybean (Thua Nao) for Biocontrol of Lasiodiplodia theobromae
}

\author{
E. CHUKEATIROTE ${ }^{1},{ }^{*}$, K. NIRAPHAI ${ }^{1}$, U. SARDSUD $^{2}$ and S. POPLUECHAI ${ }^{1}$ \\ ${ }^{1}$ School of Science, Mae Fah Luang University, Chiang Rai 57100, Thailand \\ ${ }^{2}$ Department of Biology, Faculty of Science, Chiang Mai University, Chiang Mai 50200, Thailand
}

(Received: 18 December 2017; accepted: 10 February 2018)

\begin{abstract}
In this study, bacterial biocontrol agents against the phytopathogen Lasiodiplodia theobromae were screened from Thua Nao, a Thai fermented soybean product. A total of 170 bacterial strains were isolated and initially screened for their antagonistic activity by dual culture test. Of these, 39 isolates were able to inhibit the fungal growth showing the percentage of inhibition ranging from 25.0-67.5. Among them, the isolate TN79 was selected as a potential antagonistic strain for further study. For this, the bacterial strain TN79 was cultured on nutrient agar for 2 weeks and its crude extracts were prepared using phosphate buff́́er $\mathrm{pH}$ 7.0. The bacterial crude extracts prepared were active and could inhibit all four fungal strains of $L$. theobromae. The optimum $\mathrm{pH}$ for antifungal activity of the extracts was 7. In addition, the extracts were also active when exposed to the UV light $(254 \mathrm{~nm})$ up to 1 hour and to proteinase $\mathrm{K}$ treatment $(1 \mathrm{mg} / \mathrm{ml})$. The bacterial strain TN79 was then characterized in terms of their phenotypic and genotypic properties including morphology, biochemical profiles, and rRNA gene sequence. Based on this analysis, the bacterium TN79 was closely related to Bacillus velezensis.
\end{abstract}

Keywords: Bacillus, biocontrol, fermented soybean, Lasiodiplodia, Thua Nao.

Lasiodiplodia theobromae (Pat.) Griff. and Maubl. (syn. Botryodiplodia theobromae Pat.) is an important phytopathogenic fungus causing a threatening disease for several host plants. The fungus has been associated to both tropical and subtropical plants, and causes leaf spots, necrosis, and even death of many plants including banana (Thangavelu et al., 2007), citrus (Adesemoye et al., 2014), cocoa (Mbenoun et al., 2008), mango (Mascarenhas et al., 1995), papaya (Netto et al., 2014), and other tropical fruit plants (Coutinho et al., 2017). At present, synthetic chemicals have been widely used to inhibit the phytopathogens including the fungus $L$. theobromae. Such a treatment is effective, however its use cause serious concerns related to human health and environmental issues. Besides, these chemicals can also induce the pathogen resistance, and thus future prevention can be problematic.

Biocontrol is a process of managing pests (i.e., microbial plant pathogens) using other living organisms. This is an alternative means to chemical fungicides and this treatment offers many advantages to human beings considering that it is safe and environmentally friendly. Biocontrol of the Lasiodiplodia fungus has been reported which includes Brevibacillus brevis (Che et al., 2015), Bacillus subtilis and Paenibacillus polymyxa (Sa-

* Corresponding author; e-mail: ekachai@mfu.ac.th 


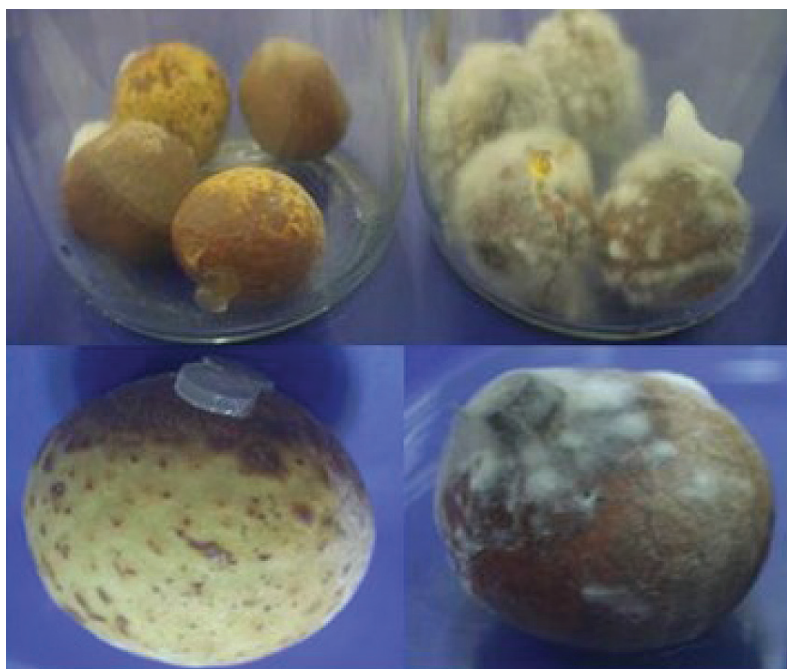

Fig. 1. Diseased symptom of longan fruit caused by Lasiodiplodia theobromae CMUL.

After 7 day incubation, the peel of the longan fruit became dark brown and covered with the fungal mycelia (right), compared with the untreated control fruits (left)

jitha et al., 2014), Trichoderma species (Mortuza and Ilag, 1999), and yeast strains (Mohamed and Saad, 2009). Bacillus species, Gram-positive, endospore-forming bacilli, are of great interest as they are able to produce a wide spectrum of secondary metabolites that have diversity in both structures and functions (Sansinenea and Ortiz, 2011). In addition, there are several reports describing the potential role of Bacillus species as the biocontrol agents (Cavaglieri et al., 2005; Melnick et al., 2008; Ali and Nadarajah, 2014). Bacillus species can be found in a wide range of habitats. Indeed, it has been reported that Bacillus species are predominant in several kinds of fermented soybean products including Thua Nao of Thailand (Chantawannakul et al., 2002; Petchkongkaew et al., 2008). Based on this information, an emphasis was placed on the isolation of Bacillus species from Thai Thua Nao. The present study also aimed to evaluate the potential use of the Bacillus strain isolated to suppress the growth of the fungus $L$. theobromae.

\section{Materials and Methods}

\section{Fungal culture}

Four Lasiodiplodia theobromae fungal strains (namely CMUL, LP1, LP2, and LG2) isolated from rotten longan fruit (Dimocarpus longan Lour.), were obtained from the Postharvest Technology Institute, Chiang Mai University, Chiang Mai, Thailand. The fungus L. theobromae strain 1120 was obtained from Department of Agriculture, Ministry of Agriculture and Cooperatives (Bangkok, Thailand). For routine cultivation, the fungal cultures were grown on potato dextrose agar (PDA; Criterion, USA) and incubated at $30{ }^{\circ} \mathrm{C}$ for 2 days. For long term storage, the fungal cultures were kept on the PDA slant at $4{ }^{\circ} \mathrm{C}$. 


\section{Screening and isolation of antagonistic bacteria}

Thai fermented soybean samples (Thua Nao) were collected from local markets in Chiang Rai, Thailand. Bacterial cultures were then isolated by serial dilution method. For this, Thua Nao sample (10.0 g) was mixed with $90 \mathrm{ml}$ of $0.1 \%(\mathrm{w} / \mathrm{v})$ peptone and decimal dilution series was performed. Aliquots $(0.1 \mathrm{ml})$ of appropriate dilutions (usually between $10^{-4}-10^{-8}$ ) were plated in triplicate on nutrient agar (NA; Criterion, USA). In total, 170 bacterial isolates were randomly selected, then purified by repeated streaking, and subsequently tested for their antagonistic activity using dual culture assay against the fungus $L$. theobromae. The dual culture tests were performed in triplicate by placing the fungal mycelia and bacterial colony on the PDA plates. For this, a mycelial agar plug ( $5 \mathrm{~mm}$ in diameter) of the fungus $L$. theobromae was placed at the centre of the PDA plate. A loopful culture of each bacterial isolates was then made at $2 \mathrm{~cm}$ juxtaposed to the fungus (Fig. 2A), and the plates were incubated at $30{ }^{\circ} \mathrm{C}$ for 24 hours. Antifungal activity was then observed by the inhibition zone of the mycelial growth. Radial growth reduction was calculated as follows: $(\mathrm{a}-\mathrm{b})$ / $\mathrm{a}$ (where $\mathrm{a}=$ radial growth measurement of the pathogen towards the direction in which there was no bacterial isolate (control), and $b$

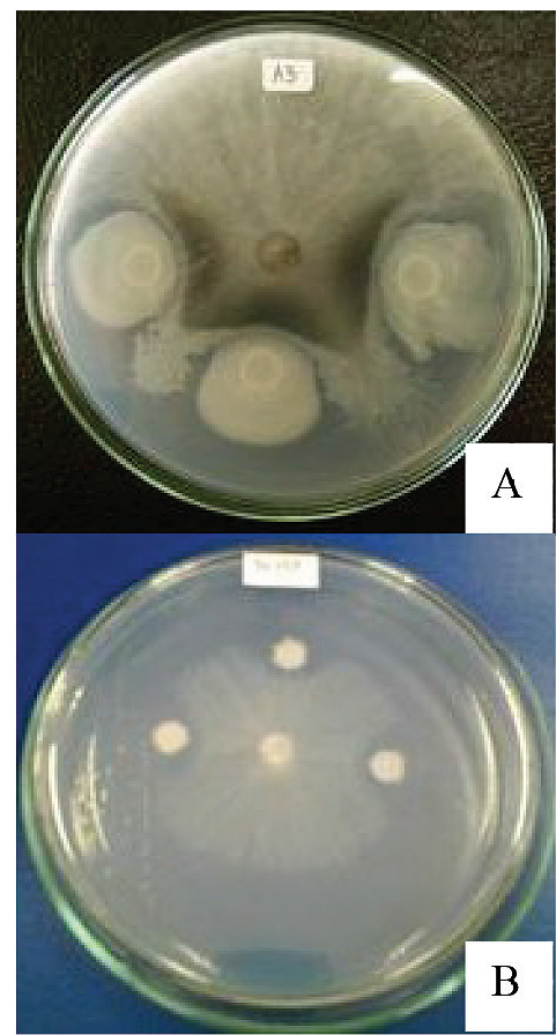

Fig. 2. Antifungal activity of the bacterial strain TN79 isolated from Thua Nao samples against Lasiodiplodia theobromae CMUL using dual culture assay. The inhibitory zones of the mycelial growth were observed when using the TN79 cells (A), and their crude extracts (B), respectively 
is that of the pathogen towards the direction in which the bacterial isolate was inoculated); these values were then expressed as percentage inhibition of radial mycelial growth. The data of the percentage inhibition of the screening were derived from the three replicates being done on the same plate (as shown in Fig. 2 as a representative). When the SD value is zero (0), the mycelial lengths were the same when moving towards the direction where the antagonists (or the extracts) were present. To confirm the results, the bacterial culture supernatants were also used. For this, a loopful of each bacterial culture was transferred to $3 \mathrm{ml}$ nutrient broth (NB; Criterion, USA) and incubated at $37{ }^{\circ} \mathrm{C}$ for 24 hours. An overnight bacterial culture was pelleted by centrifugation at $15,000 \mathrm{rpm}$ at $4{ }^{\circ} \mathrm{C}$ for 10 min. The culture supernatant was then collected and used instead of the bacterial cells in determining an inhibitory activity (Fig. 2B). The bacterial isolates exhibiting the greatest zones of inhibition were selected for further experiment.

\section{Characterisation of antifungal metabolites produced by the strain TN79}

Initially, the bacterial strain TN79 was cultivated on NA plates for 2 weeks at $37^{\circ} \mathrm{C}$. The bacterial extracts were then prepared using a solid phase extraction method. For this procedure, the bacterial cultures were macerated with $15 \mathrm{ml}$ phosphate buffer $\left(\mathrm{pH} 7.0 ; 0.144 \% \mathrm{Na}_{2} \mathrm{HPO}_{4}, 0.024 \% \mathrm{KH}_{2} \mathrm{PO}_{4}\right.$ ) using a sterile stainless blender (Waring $800 \mathrm{BU})$. The agar slurry was gently vortexed and subsequently centrifuged to separate the solid and solvent phase. The solvent phase was then collected and the agar solid was re-extracted twice. All these extracts were combined, filtered $(0.45 \mu \mathrm{m})$, and transferred to a vial. The crude extracts were then stored at $4{ }^{\circ} \mathrm{C}$ in airtight bottles until use.

The effect of $\mathrm{pH}$ on the antifungal activity of the crude extracts produced by the strain TN79 was also studied. The pH of the phosphate buffer was adjusted in a range of 4-9 using hydrochloric acid (1 M) and sodium hydroxide (1 M), and subsequently used for crude extract preparation. In addition, the crude extracts were also treated with proteinase $\mathrm{K}(1 \mathrm{mg} / \mathrm{ml})$ (Merck, Germany) for $1 \mathrm{~h}$, and exposed to the UV light (in the UVC range of $254 \mathrm{~nm}$ ) at a distance of $15 \mathrm{~cm}$ for 30-60 min. The antifungal activity of the metabolites was then tested as previously described.

\section{Statistical analysis}

Data of percent inhibition of the fungal growth obtained from the dual culture test of the bacterial isolates and their culture supernatants were subjected to a simple descriptive statistics, and expressed as means and standard deviation (SD) values.

\section{Identification of antagonistic bacteria}

The bacterial strain TN79 exhibiting highest antifungal activity was selected for identification. Conventional methods including Gram-staining, presence of spore, oxygen requirement, catalase test, lecithinase test, ability to growth in 5 and $7 \% \mathrm{NaCl}$, growth at 50 and $65^{\circ} \mathrm{C}, \mathrm{IMViC}$ test, nitrate reduction, fermentation of glucose, arabinose, xylose, and sucrose, and starch hydrolysis, were adopted (MacFaddin, 2000). Further characterization was undertaken using $16 \mathrm{~S}$ rRNA gene sequence analysis. For this, the genomic DNA of the isolate TN79 was extracted by the standard protocol of Sambrook and Green 
(2012). The $16 \mathrm{~S}$ rRNA encoding gene was then amplified using primers $63 \mathrm{f}$ (5'-CAG GCC TAA CAC ATG CAA GTC-3') and 1387r (5'-GGG CGG WGT GTA CAA GGC-3') (Marchesi et al., 1998). The polymerase chain reaction was performed in a $25 \mu 1$ reaction consisting of $10 \mathrm{X}$ PCR buffer, $50 \mathrm{mM} \mathrm{MgCl}_{2}, 2 \mathrm{mM}$ of each dNTP, $1 \mathrm{mM}$ of each primer, 5 Units Taq polymerase, and bacterial DNA ( $1 \mu 1)$. Amplification protocol consisted of an initial denaturation at $94{ }^{\circ} \mathrm{C}$ for $5 \mathrm{~min}$, followed by 35 cycles of $94{ }^{\circ} \mathrm{C}$ for $30 \mathrm{sec}, 55^{\circ} \mathrm{C}$ for $30 \mathrm{sec}$, and $72{ }^{\circ} \mathrm{C}$ for $30 \mathrm{sec}$, and a final extension of $72{ }^{\circ} \mathrm{C}$ for $5 \mathrm{~min}$. The amplified products were electrophoresed in $0.8 \%$ agarose gel, and subsequently purified using TaKaRa SUPRECTM-PCR (TaKaRa, Japan). The purified products were then sequenced and the sequencing data were analyzed using BLAST (Altschul et al., 1990) and the closest known species were determined based on the percentages of sequence similarity. The accession numbers of the 16S rRNA gene sequence of the bacterial isolate TN79 deposited in GenBank was EU590118. Sequence alignment and phylogenetic analysis were then carried out using the Phylogeny.fr software (Dereeper et al., 2010).

\section{Results and Discussion}

\section{Pathogenicity of Lasiodiplodia theobromae}

Initially, L. theobromae fungal strains were tested for their pathogenicity. For this, a piece of mycelial agar plug was placed on the surface sterilized longan fruit, and incubated at room temperature for 7 days. It was observed that the diseased symptom was developed after incubating for 3 days. For treated longan fruit, the exocarp area where the fungal agar plug was placed, turned dark brown and became rotten. Besides, the mycelial growth was observed on the fruits. This diseased symptom did not occur on the untreated control fruits (Fig. 1).

\section{Isolation and screening of antagonistic bacteria}

In this study, Thua Nao samples were used to isolate the bacteria with antifungal property. A total of 170 bacterial strains were isolated, and initially characterized as endospore-forming bacilli. All bacterial isolates were then screened for antifungal activity against $L$. theobromae, using the dual culture method. Of 170 isolates, it was found that 39 isolates $(22.94 \%)$ were able to inhibit the fungal growth with the percentage of inhibition ranging from 25.0-67.5 (Table 1). To confirm the antagonistic activity, the culture supernatants of these bacterial isolates were prepared and used in the dual culture assay. By this means, 36 isolates were active showing an inhibitory zone. Of these, the bacterial isolate TN79 exhibited highest antifungal activity when using both cell and culture supernatant (Table 1 and Fig. 2).

\section{Characterisation of antifungal metabolites produced by the strain TN79}

In this study, the crude extracts of the bacterial strain TN79 were prepared using the solid state condition. The antifungal activity of the TN79 crude extracts was then tested 
Table 1

Preliminary screening of bacterial strains isolated from Thua Nao samples capable of inhibiting the growth of Lasiodiplodia theobromae fungus strain CMUL using dual culture test

\begin{tabular}{|c|c|c|}
\hline Bacterial isolates & $\%$ Inhibition (supernatants) & $\%$ Inhibition (cells) \\
\hline TN79 & $52.0 \pm 0$ & $60.0 \pm 0.58$ \\
\hline TN112 & $52.0 \pm 0.58$ & $40.0 \pm 1.15$ \\
\hline TN117 & $51.2 \pm 0$ & $37.5 \pm 0$ \\
\hline TN142 & $49.4 \pm 0.58$ & $27.5 \pm 1.53$ \\
\hline TN133 & $47.6 \pm 0$ & $60.0 \pm 0.58$ \\
\hline TN3 & $46.2 \pm 1.00$ & $45.0 \pm 0$ \\
\hline $\mathrm{TN} 2$ & $45.7 \pm 1.00$ & $32.5 \pm 0$ \\
\hline TN119 & $45.3 \pm 0$ & $30.0 \pm 1.00$ \\
\hline TN129 & $44.0 \pm 0$ & $25.7 \pm 0$ \\
\hline TN188 & $44.0 \pm 1.15$ & $37.5 \pm 2.08$ \\
\hline TN107 & $43.9 \pm 0$ & $25.0 \pm 0$ \\
\hline TN6 & $42.7 \pm 1.00$ & $37.5 \pm 0.58$ \\
\hline TN5 & $41.0 \pm 1.15$ & $50.0 \pm 0$ \\
\hline TN9 & $41.0 \pm 0$ & $27.5 \pm 2.31$ \\
\hline TN92 & $41.0 \pm 2.08$ & $45.0 \pm 2.31$ \\
\hline TN59 & $40.0 \pm 0$ & $37.5 \pm 0$ \\
\hline TN153 & $38.7 \pm 0$ & $27.5 \pm 1.00$ \\
\hline TN147 & $38.3 \pm 2.31$ & $27.5 \pm 0$ \\
\hline TN130 & $37.2 \pm 0$ & $37.1 \pm 0$ \\
\hline TN168 & $36.1 \pm 2.31$ & $50.0 \pm 0$ \\
\hline TN68 & $34.7 \pm 0$ & $50.0 \pm 0.58$ \\
\hline TN125 & $34.6 \pm 0.58$ & $55.0 \pm 0$ \\
\hline TN121 & $33.3 \pm 0.58$ & $30.0 \pm 0$ \\
\hline TN16 & $33.3 \pm 0$ & $45.0 \pm 1.00$ \\
\hline TN101 & $30.8 \pm 0$ & $30.0 \pm 0$ \\
\hline TN28 & $29.6 \pm 0.58$ & $50.0 \pm 0$ \\
\hline TN134 & $28.0 \pm 0$ & $48.6 \pm 1.15$ \\
\hline TN8 & $28.0 \pm 1.15$ & $32.5 \pm 1.53$ \\
\hline TN11 & $26.9 \pm 1.00$ & $67.5 \pm 2.31$ \\
\hline TN114 & $26.7 \pm 0$ & $27.5 \pm 0.58$ \\
\hline TN149 & $21.3 \pm 1.00$ & $48.6 \pm 0$ \\
\hline TN126 & $20.3 \pm 0.58$ & $37.5 \pm 1.00$ \\
\hline TN141 & $20.3 \pm 0$ & $30.0 \pm 1.00$ \\
\hline TN148 & $17.9 \pm 0$ & $45.0 \pm 0$ \\
\hline TN144 & $17.3 \pm 2.31$ & $30.0 \pm 2.08$ \\
\hline TN122 & $7.2 \pm 2.08$ & $42.9 \pm 0.58$ \\
\hline CMU3 & $1.3 \pm 0$ & $45.9 \pm 0$ \\
\hline TN103 & $0.0 \pm 0$ & $37.5 \pm 0.58$ \\
\hline TN25 & $0.0 \pm 0$ & $30.0 \pm 0$ \\
\hline TN90 & $0.0 \pm 0$ & $37.5 \pm 0.58$ \\
\hline
\end{tabular}

Note: The data of the percentage inhibition of the screening were derived from the three replicates being done on the same plate (as shown in Fig. 2 as a representative). When the SD value is zero $(0)$, the mycelial lengths were the same when moving towards the direction where the antagonists (or the extracts) were present. 
Table 2

Inhibitory activity on Lasiodiplodia theobromae strain CMUL of the TN79 crude extracts after treatment with proteinase K and UV. Data presented were the percentage of inhibition

\begin{tabular}{lc}
\hline Treatment of TN79 extracts & Percentage of inhibition \\
\hline Control & $34.78 \pm 1.00$ \\
Proteinase K $(1 \mathrm{mg} / \mathrm{ml})$ & $33.33 \pm 0.58$ \\
UV - 30 min & $34.72 \pm 0.58$ \\
UV - 60 min & $34.72 \pm 0.58$ \\
\hline
\end{tabular}

Table 3

Percentage of inhibition of Lasiodiplodia theobromae growth by the bacterium strain TN79. Data presented were the percentage of inhibition when using the bacterial cells and the bacterial crude extracts (in parentheses)

\begin{tabular}{ll}
\hline Fungal strains & \multicolumn{1}{c}{ Percentage of inhibition } \\
\hline CMUL & $60.0 \pm 0(52.0 \pm 0)$ \\
LP1 & $40.0 \pm 0(17.39 \pm 0.58)$ \\
LP2 & $50.0 \pm 0(26.09 \pm 0)$ \\
LG2 & $47.8 \pm 0(34.78 \pm 0)$ \\
1120 & $52.2 \pm 0(12.50 \pm 0)$ \\
\hline
\end{tabular}

Note: The data of the percentage inhibition of the screening were derived from the three replicates being done on the same plate (as shown in Fig. 2 as a representative). When the SD value is zero (0), the mycelial lengths were the same when moving towards the direction where the antagonists (or the extracts) were present.

for stability in terms of $\mathrm{pH}$ (Fig. 3). Our data revealed that the crude extracts of the isolate TN79 was active in a $\mathrm{pH}$ range of 6-9 with ca. 15-35\% inhibition although it should be noted that there was no activity under strong acidic condition $(\mathrm{pH}<5)$. In addition, there was no effect of the proteinase treatment and UV exposure on the antifungal property of the TN79 crude extracts (Table 2). It should also be noted that the TN79 crude extracts were active against all five strains of $L$. theobromae used in the study (Table 3 ).

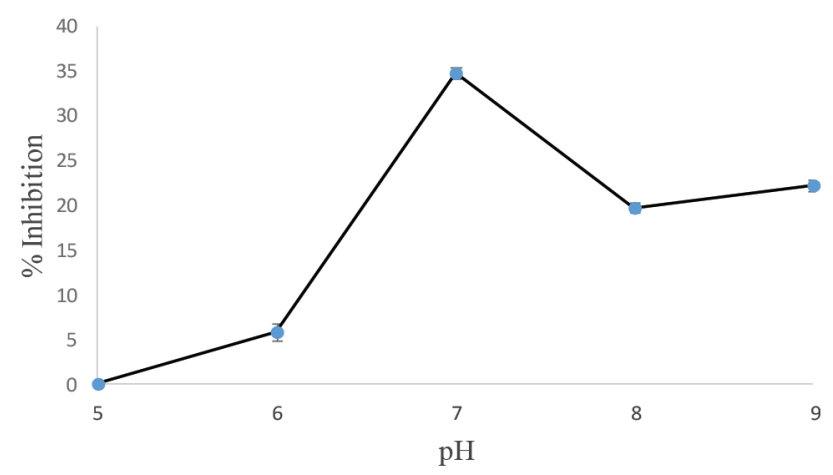

Fig. 3. Effect of $\mathrm{pH}$ on the antifungal activity of the TN79 crude extracts. The $\mathrm{pH}$ of the culture supernatant of the bacterial strain TN79 was adjusted to $\mathrm{pH} 5-9$, and the extract's stability was tested against the fungus Lasiodiplodia theobromae CMUL 
Table 4

Morphological, physiological and biochemical characteristics of the bacteria strain TN79 isolated from Thua Nao

\begin{tabular}{|c|c|c|c|}
\hline Characteristics & TN79 & B. subtilis & B. licheniformis \\
\hline Shape of cells & Rod & Rod & Rod \\
\hline Gram reaction & + & + & + \\
\hline Spore position & Central & Central & Central \\
\hline Catalase & + & $+1-$ & + \\
\hline Glucose fermentaion & + & + & + \\
\hline Mannitol fermentation & + & + & + \\
\hline Xylose fermentation & + & + & + \\
\hline Arabinose fermentation & + & + & + \\
\hline Starch hydrolysis & + & + & + \\
\hline Growth in $7.5 \% \mathrm{NaCl}$ & + & + & + \\
\hline Citrate utilisation & + & + & + \\
\hline Methyl red test & - & - & - \\
\hline Voges-Proskeaur test & + & + & + \\
\hline Indole production & - & - & - \\
\hline Motility & + & + & + \\
\hline
\end{tabular}

Microbes are able to produce a wide spectrum of secondary metabolites. These are diverse in terms of structure and function. For example, Bacillus species can produce a wide range of active compounds including peptide antibiotics (Amin et al., 2012), lipopeptides (Ramarathnam et al., 2007), and other miscellaneous compounds (Sansinenea and Ortiz, 2011). Antimicrobial agents in the crude extracts of the TN79 bacilli are of great interest as they were resistant to proteinase $\mathrm{K}$ treatment and UV exposure. Therefore, an elucidation of the TN79 active components should be further explored.

\section{Identification of the bacteria isolate TN79}

As described above, the bacteria strain TN79 exhibiting highest antagonistic activity (Table 1) was then studied for its identity. For this, the isolate TN79 was morphologically studied and subject to a series of biochemical tests as shown in Table 4. The isolate TN79 was Gram positive, endospore-forming, rod-shaped bacteria. Based on its biochemical profiles (i.e., facultative anaerobic, catalase, oxidase, and nitrate reductase positive reactions), the isolate TN79 exhibited similar profile to those of Bacillus subtilis and B. licheniformis (Priest et al., 1987).

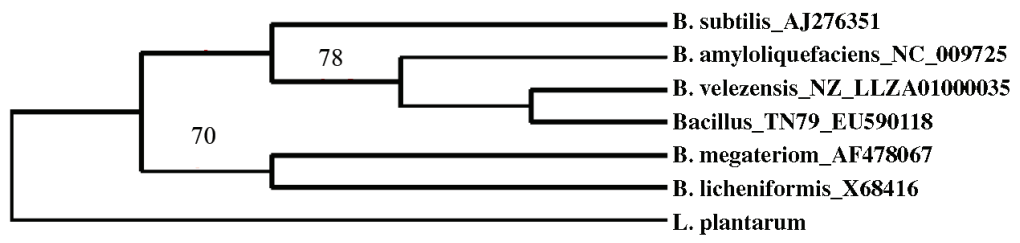

Fig. 4. Dendogram showing relationships between the strain TN79 and other Bacillus species based on their 16S rRNA gene sequences. Numbers at nodes represent the percentages of occurrence of nodes in 1000 bootstrap trials 
Assignment of the strain to the genus Bacillus was confirmed by $16 \mathrm{~S}$ rRNA gene sequencing study. The 16S rRNA gene sequence of the isolate TN79 was determined initially using a BLAST search GenBank database (Altschul et al., 1990). The 16S rRNA gene sequence of the strain TN79 was closely related to B. velezensis (99.90\%). Phylogenetic tree was then generated to determine the phylogeny of the strain TN79 and its related Bacillus species (Fig. 4). According to Fig. 4, the strain TN79 was in the same clade of $B$. velezensis. Previous study has proposed that $B$. subtilis is a species complex and probably consists of $B$. amyloliquefaciens, B. licheniformis, B. mojavensis, and B. sonorensis (Rooney et al., 2009). Interestingly, Bacillus species closely related to B. subtilis exhibit similar phenotypic and genotypic characteristics. Consequently, we would propose that the isolate TN79 was classified in B. subtilis group at present.

\section{Conclusions}

In the present study, we identified the bacteria strain TN79 isolated from Thua Nao, as a potential biocontrol agent that can be used to suppress the growth of the fungal pathogen L. theobromae. This study is one of the few studies describing the antifungal activity of the bacteria against $L$. theobromae. This potential should be further undertaken especially for elucidating the active components in the crude extracts of the isolate TN79. A field application of the isolate TN79 should also be further explored and this would evaluate the utility of the TN79 agent for biological control of the postharvest diseases caused by this fungus.

\section{Acknowledgement}

This work was financially supported by Mae Fah Luang University.

\section{Literature}

Adesemoye, A. O., Mayorquin, J. S., Wang, D. H., Twizeyimana, M., Lynch, S. C. and Eskalen, A. (2014): Identification of species of Botryosphaeriaceae causing bot gummosis in citrus in California. Plant Dis. 98, 55-61.

Ali, H. and Nadarajah, K. (2014): Evaluating the efficacy of Trichoderma spp and Bacillus subtilis as biocontrol agents against Magnaporthe grisea in rice. Australian J. Crop Sci. 8, 1324-1335.

Altschul, S. F., Gish, W., Miller, W., Myers, E. W. and Lipman, D. J. (1990): Basic local alignment search tool. J. Mol. Biol. 215, 403-410.

Amin, A., Khan, M. A., Ehsanullah, M., Haroon, U., Azam, S. M. F. and Hameed, A. (2012): Production of peptide antibiotics by Bacillus sp. GU 057 indigenously isolated from saline soil. Brazilian J. Microbiol. $43,1340-1346$.

Cavaglieri, L., Orlando, J., Rodríguez, M. I., Chulze, S. and Etcheverry, M. (2005): Biocontrol of Bacillus subtilis against Fusarium verticillioides in vitro and at the maize root level. Res. Microbiol. 156, 748-754.

Chantawannakul, P., Onchaeroen, A., Klanbut, K., Chukeatorite, E. and Lumyong, S. (2002): Characterization of proteases of Bacillus subtilis strain 38 isolated from traditionally fermented soybean in Northern Thailand. ScienceAsia 28, 241-245.

Che, J., Liu, B., Ruan, C., Tang, J. and Huang, D. (2015): Biocontrol of Lasiodiplodia theobromae, which causes black spot disease of harvested wax apple fruit, using a strain of Brevibacillus brevis FJAT-0809-GLX. Crop Prot. 67, 178-183. 
Coutinho, I. B. L., Freire, F. C. O., Lima, C. S., Lima, J. S., Gonçalves, F. J. T., Machado, A. R., Silva, A. M. S. and Cardoso, J. E. (2017): Diversity of genus Lasiodiplodia associated with perennial tropical fruit plants in northeastern Brazil. Plant Pathol. 66, 90-104.

Dereeper, A., Audic, S., Claverie, J. M. and Blanc, G. (2010): BLAST-EXPLORER helps you building datasets for phylogenetic analysis. BMC Evol. Biol., 10, 8 .

MacFaddin, J. F. (2000): Biochemical tests for identification of medical bacteria. Lippincott Williams and Wilkins, Philadelphia, USA, 928 p.

Marchesi, J. R., Sato, T., Weightman, A. J., Martin, T. A., Fry, J. C., Hiom, S. J. and Wade, W. G. (1998): Design and evaluation of useful bacterium-specific PCR primers that amplify genes coding for bacterial $16 \mathrm{~S}$ rRNA. Appl. Env. Microbiol. 64, 795-799.

Mascarenhas, P., Behere, A., Sharma, A. and Padwal-Desai, S. R. (1995): Post-harvest spoilage of mango (Mangifera indica) by Botryodiplodia theobromae. Mycol. Res. 100, 27-30.

Mbenoun, M., Momo, Z. E. H., Samuels, G., Nsouga, A. F. and Nyasse, S. (2008): Dieback due to Lasiodiplodia theobromae, a new constraint to cocoa production in Cameroon. Plant Pathol. 57, 381.

Melnick, R. L., Zidack, N. K., Bailey, B. A., Maximova, S. N., Guiltinan, M. and Backman, P. A. (2008): Bacterial endophytes: Bacillus spp. from annual crops as potential biological control agents of black pod rot of cacao. Biol. Control 46, 46-56.

Mohamed, H. and Saad, A. (2009): The biocontrol of postharvest disease (Botryodiplodia theobromae) of guava (Psidium guajava L.) by the application of yeast strains. Postharvest Biol. Technol. 53, 123-130.

Mortuza, M. G. and Ilag, L. L. (1999): Potential for biocontrol of Lasiodiplodia theobromae (Pat.) Griff. and Maubl. in banana fruits by Trichoderma species. Biol. Control 15, 235-240.

Netto, M. S. B., Assuncao, I. P. and Lima, G. S. A. (2014): Species of Lasiodiplodia associated with papaya stem-end rot in Brasil. Fungal Div. 67, 127-141.

Petchkongkaew, A., Taillandier, P., Gasaluck, P. and Lebrihi, A. (2008): Isolation of Bacillus spp. from Thai fermented soybean (Thua-nao): screening for aflatoxin B1 and ochratoxin A detoxification. J. Appl. Microbiol. 104, 1495-1502.

Priest, F. G., Goodfellow, M., Shute, L. A. and Berkeley, R. C. W. (1987): Bacillus amylolique faciens sp. nov., nom. rev. Int. J. Syst. Bacteriol. 37, 69-71.

Ramarathnam, R., Bo, S., Chen, Y., Fernando, W. G., Xuewen, G. and de Kievit, T. (2007): Molecular and biochemical detection of fengycin- and bacillomycin D-producing Bacillus spp., antagonistic to fungal pathogens of canola and wheat. Can. J. Microbiol. 53, 901-911.

Rooney, A. P., Price, N. P. C., Ehrhardt, J. L., Swezey, J. L. and Bannan, J. D. (2009): Phylogeny and molecular taxonomy of the Bacillus subtilis species complex and description of Bacillus subtilis subsp. inaquosorum subsp. nov. Int. J. Syst. Evol. Microbiol. 59, 2429-2436.

Sajitha, K. L., Florence, E. J. M. and Dev, S. A. (2014): Screening of bacterial biocontrols against sapstain fungus (Lasiodiplodia theobromae Pat.) of rubberwood (Hevea brasiliensis Muell.Arg.). Res. Microbiol. $165,541-548$.

Sambrook, J. and Green, M. R. (2012): Molecular Cloning: a Laboratory Manual. 4th ed. Cold Spring Harbor Laboratory Press, New York, 545 p.

Sansinenea, E. and Ortiz, A. (2011): Secondary metabolites of soil Bacillus spp. Biotechnol. Lett. 33, 15231538.

Thangavelu, R., Sangeetha, G. and Mustaffa, M. M. (2007): Cross-infection potential of crown rot pathogen (Lasiodiplodia theobromae) isolates and their management using potential native bioagents in banana. Australas. Plant Pathol. 36, 595-605. 